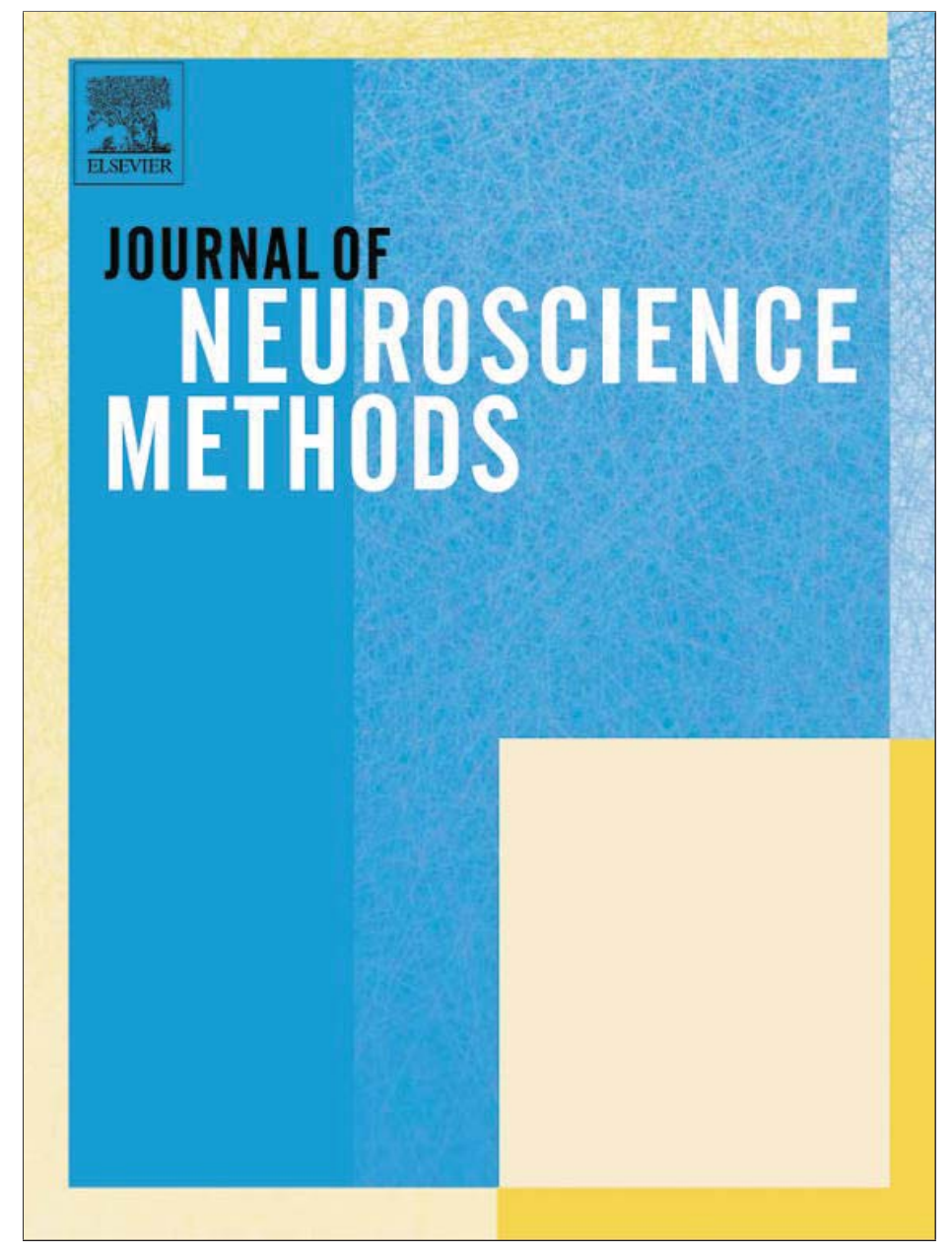

(This is a sample cover image for this issue. The actual cover is not yet available at this time.)

This article appeared in a journal published by Elsevier. The attached copy is furnished to the author for internal non-commercial research and education use, including for instruction at the authors institution and sharing with colleagues.

Other uses, including reproduction and distribution, or selling or licensing copies, or posting to personal, institutional or third party websites are prohibited.

In most cases authors are permitted to post their version of the article (e.g. in Word or Tex form) to their personal website or institutional repository. Authors requiring further information regarding Elsevier's archiving and manuscript policies are encouraged to visit: 
Basic Neuroscience

\title{
Brain nitric oxide: Regional characterisation of a real-time microelectrochemical sensor
}

\author{
Niall J. Finnerty ${ }^{\mathrm{a}, *}$, Saidhbhe L. O'Riordan ${ }^{\mathrm{a}}$, Erik Palsson ${ }^{\mathrm{b}}$, John P. Lowry ${ }^{\mathrm{a}}$ \\ a Sensors Development Unit and Neurochemistry Research Unit, BioAnalytics Laboratory, Department of Chemistry, National University of Ireland Maynooth, Co. Kildare, Ireland \\ ${ }^{\mathrm{b}}$ Department of Psychiatry and Neurochemistry, Institute of Neuroscience and Physiology, The Sahlgrenska Academy at University of Gothenburg, Sweden
}

\section{A R T I C L E I N F O}

Article history:

Received 13 April 2012

Received in revised form 17 May 2012

Accepted 21 May 2012

\section{Keywords:}

Nitric oxide

Real-time

Prefrontal cortex

Nucleus accumbens

In vivo

\begin{abstract}
A B S T R A C T
A reliable method of directly measuring endogenously generated nitric oxide (NO) in real-time and in various brain regions is presented. An extensive characterisation of a previously described amperometric sensor has been carried out in the prefrontal cortex and nucleus accumbens of freely moving rats. Systemic administration of saline caused a transient increase in signal from baseline levels in both the prefrontal cortex $(13 \pm 3 \mathrm{pA}, n=17)$ and nucleus accumbens $(12 \pm 3 \mathrm{pA}, n=8)$. NO levels in the prefrontal cortex were significantly increased by $43 \pm 9 \mathrm{pA}(n=9)$ following administration of L-arginine. A similar trend was observed in the nucleus accumbens, where an increase of $44 \pm 9 \mathrm{pA}(n=8)$ was observed when compared against baseline levels. Systemic injections of the non-selective NOS inhibitor L-NAME produced a significant decrease in current recorded in the prefrontal cortex ( $24 \pm 6 \mathrm{pA}, n=5)$ and nucleus accumbens $(17 \pm 3 \mathrm{pA}, n=6)$. Finally it was necessary to validate the sensors functionality in vivo by investigating the effect of the interferent ascorbate on the oxidation current. The current showed no variation in both regions over the selected time interval of $60 \mathrm{~min}$, indicating no deterioration of the polymer membrane. A detailed comparison identified significantly greater affects of administrations on NO sensors implanted in the striatum than those inserted in the prefrontal cortex and the nucleus accumbens.
\end{abstract}

(c) 2012 Elsevier B.V. All rights reserved.

\section{Introduction}

Since its emergence as a signalling molecule in the brain 20 years ago, nitric oxide (NO) has been implicated in many different functions that are determined by the source of the nitric oxide synthase (NOS) enzyme used in its synthesis. Three isozymes have so far been identified; endothelial NOS (eNOS), neuronal NOS (nNOS) and inducible NOS (iNOS) (Alderton et al., 2001; Bruckdorfer, 2005; Kelm, 1999; Kiechle and Malinski, 1993). Endothelial cells are probably the major, if not the sole, location of eNOS in the brain with emerging evidence of its role in regulating brain function, independent of its role in the vasculature (Garthwaite, 2008). Neuronal NOS is the most abundantly present isoform in the brain and is tightly associated with NMDA receptor function on post-synaptic membranes. The inducible form, which is $\mathrm{Ca}^{2+}$ independent and produced in large amounts in response to an external stimulus such as infection or inflammation, carries out its role following release from macrophages (Bruckdorfer, 2005).

NO's diverse functions include a neurological function in synaptic plasticity, neurotransmission, learning and memory (Garthwaite, 2008; Wass et al., 2006a,b), in addition to having a

\footnotetext{
* Corresponding author. Tel.: +353 1708 6477; fax: +3531 7083815.

E-mail address: niall.finnerty@nuim.ie (N.J. Finnerty).
}

primary role in non-specific immunity (Bruckdorfer, 2005), penile erection (Escrig et al., 1999; Mas et al., 2002) and platelet aggregation inhibition (Radomski et al., 1990). While NO is responsible for normal synaptic transmission, excess levels of NO have been portrayed as being neurotoxic (Barth et al., 1997; Espey et al., 2002). Glutamate neurotoxicity is hypothesised to occur primarily due to release of NO from glial cells, via activation of the ionotropic glutamate NMDA receptor (Dawson et al., 1996). Barth et al. (1997) found that NO produced in response to ischaemia and mediated by glutamate release can cause neuronal cell death, effects which were largely prevented by use of NOS inhibitors.

It is hypothesised that the prefrontal cortex serves a specific function in cognitive control in the brain; impairments of this brain region have been implicated in schizophrenia giving rise to negative symptoms and cognitive dysfunctions associated with the disease (Fejgin et al., 2008; Miller and Cohen, 2001; Tzschentke, 2001). The nucleus accumbens which is part of the ventral striatum is assumed to play a role in reward, emotion and addiction (Saul'skaya and Fofonova, 2009; Saul'skaya et al., 2008; Saulskaya and Fofonova, 2006; Savel'ev and Saul'skaya, 2007; Yananli et al., 2007) and it too is postulated to have a function in the pathophysiology of schizophrenia. Recent findings have postulated that the NO pathway may constitute an interesting target for novel pharmacological therapies in schizophrenia and possibly play a role in the pathophysiology of the disorder. However, this contention 
rests on indirect evidence as suitable tools for the real-time detection of NO in vivo have, until recently, been lacking (Palsson et al., 2009). This has also been highlighted recently by Garthwaite, who expressed a great need for a reliable method of directly measuring endogenously generated NO in tissues with the necessary sensitivity or spatial and temporal precision (Garthwaite, 2008). We have previously reported the in vitro (Brown et al., 2009; Brown and Lowry, 2003) and in vivo (Finnerty et al., 2012) characterisation of a Nafion ${ }^{\circledR}$-modified Pt sensor designed for real-time monitoring of brain extracellular NO. In vitro findings confirmed that the Nafion ${ }^{\circledR}(5 / 2)$ sensor had a response time suitable for in vivo monitoring, linearity over the relevant concentration range for NO, freedom from protein and lipid fouling, and minimal interference from a variety of endogenous species, including ascorbic acid, dopamine and serotonin over physiologically relevant concentration ranges. A detailed in vivo characterisation was carried out in the striatum of wistar rats and significant NO changes were recorded against baseline following administrations of stock NO, L-arginine and L-NAME. Ascorbate selectivity studies confirmed minimal deterioration of the Nafion ${ }^{\circledR}$-modified surface and the stability of the sensor was analysed over 8 days confirming no significant change in baseline. We investigated the application of the NO sensor in a study carried out utilising the psychotomimetic drug phencyclidine hydrochloride (PCP), which was found to induce a dose-dependent increase in prefrontal cortex NO levels, thus corroborating previous indirect evidence of this effect of PCP. In addition, the PCP-induced elevation of NO could be counteracted by pretreatment with the NOS inhibitor, L-NAME, in a dose that has previously been shown to block the behavioural effects of PCP in translational animal models of schizophrenia (Klamer et al., 2004a, 2001; Palsson et al., 2009; Wass et al., 2006a,b). This study has provided the first direct biochemical evidence for an involvement of NO in the effects of the NMDA receptor antagonist PCP.

In the present study an extensive characterisation of the Nafion ${ }^{\circledR}(5 / 2)$-modified Pt sensor was carried out in the prefrontal cortex and nucleus accumbens of awake freely moving rats. These two brain regions were chosen due to their high density of NMDA receptors (Monaghan and Cotman, 1985) and their hypothesised roles in the pathophysiology of schizophrenia (Fejgin et al., 2008). Secondly, a comparative analysis was undertaken between the Nafion ${ }^{\circledR}(5 / 2)$-modified Pt sensors implanted in the prefrontal cortex, nucleus accumbens and striatum.

\section{Materials and methods}

\subsection{Chemicals and solutions}

All chemicals used throughout the experiments were purchased from Sigma Chemical Co. (Dublin, Ireland). A 0.9\% solution of saline was prepared by dissolving $0.9 \mathrm{~g} \mathrm{NaCl}$ in $100 \mathrm{~mL}$ doubly distilled water. In all cases, unless otherwise noted all systemic administration of L-arginine $\left(300 \mathrm{mg} \mathrm{kg}^{-1}\right), \mathrm{L}-\mathrm{N}^{\mathrm{G}}$-nitroarginine methyl ester hydrochloride (L-NAME, $30 \mathrm{mg} \mathrm{kg}^{-1}$ ), and sodium ascorbate $\left(2 \mathrm{~g} \mathrm{~kg}^{-1}\right)$ were made up in a solution of $0.9 \%$ saline.

\subsection{NO sensor preparation}

Nafion ${ }^{\circledR}(5 / 2)$-coated Pt disk electrodes were made from Teflon ${ }^{\circledR}$-insulated platinum/iridium (Pt/Ir 90\%/10\%) wire $(125 \mu \mathrm{m}$ bare diameter 5T, Advent Research Materials, Suffolk, UK). The electrodes were approximately $4 \mathrm{~cm}$ in length and were prepared by carefully cutting $2 \mathrm{~mm}$ of Teflon ${ }^{\circledR}$ insulation from one end of the wire and soldering to this end a gold clip which provided rigidity and electrical contact. The other end of the wire acted as the active (disk) surface. The electrode was modified as previously described (Brown et al., 2009; Brown and Lowry, 2003; Finnerty et al., 2012).

\subsection{Systemic administrations}

All systemic administrations were carried out in $1 \mathrm{~mL}$ saline by intraperitoneal (i.p.) injection.

\subsection{In vivo implantation and surgery protocol}

Male Wistar rats (Biomedical Facility, University College Dublin, Ireland) weighing between 200 and $300 \mathrm{~g}$ were housed in a temperature $\left(17-23^{\circ} \mathrm{C}\right)$, humidity and light-controlled $(12 \mathrm{~h}$ light, $12 \mathrm{~h}$ dark cycle) environment with access to food ad libitum prior to surgery. NO sensors were implanted following a previously described procedure (Lowry et al., 1997). Coordinates for the prefrontal cortex and nucleus accumbens with the skull levelled between bregma and lambda, were: $\mathrm{A} / \mathrm{P}+3.2, \mathrm{M} / \mathrm{L} \pm 0.8$ from bregma and $\mathrm{D} / \mathrm{V}-4.2$ from dura and $\mathrm{A} / \mathrm{P}+1.85, \mathrm{M} / \mathrm{L} \pm 1.3$ from bregma and $\mathrm{D} / \mathrm{V}-6.8$ from dura respectively (Paxinos and Watson, 1998). A reference and auxiliary electrode (8T Ag wires, $200 \mu \mathrm{m}$ bare diameter) were placed in the cortex. The reference potential provided by the bare Ag wire in brain tissue is very similar to that of the saturated calomel electrode (SCE) used in the in vitro characterisation (O'Neill et al., 1998). The electrodes and probe were fixed to the skull with dental screws and dental acrylate (Associated Dental Products, Swindon, UK). The rats were anesthetised with the volatile anaesthesia Isoflurane, placed in a Kopf stereotaxic instrument and kept on a heating pad to prevent hypothermia. A $1 \mathrm{~mL} / \mathrm{kg}$ injection of the opioid analgesic buprenorphine is administered subcutaneously (s.c.) $30 \mathrm{~min}$ after the end of the surgery and the animal allowed to rest. The animal is monitored for the next few hours, before being transferred to a holding bowl where it remains for the duration of the experiment. The animal is allowed to recover for at least $24 \mathrm{~h}$ prior to connection to the potentiostat. The desired potential ( $+900 \mathrm{mV}$ vs. Ag wire) is then applied to the NO sensor and the current is allowed to stabilise for approximately $24 \mathrm{~h}$. Following this period of stabilisation, in vivo measurements were commenced. All experimental procedures were performed under license in accordance with the European Communities Regulations 2002 (Irish Statutory Instrument 566/2002 and U.K. Animals (Scientific Procedures) Act 1986).

\subsection{Instrumentation and software}

Constant potential amperometry was performed using previously described methods (Brown et al., 2009; Finnerty et al., 2012). All data presented had baselines normalised to zero to show the change in current $(\Delta I)$ and reported concentration changes are based on a previously reported protocol (Finnerty et al., 2012). The significance of differences observed was estimated using the Student's $t$-test for paired or unpaired observations where appropriate. Two-tailed levels of significance were used with $p<0.05$ considered to be significant. All data are presented as mean \pm standard error (SEM), with $n=$ number of sensors implanted in 8 animals (saline - prefrontal cortex), 4 animals (saline - nucleus accumbens), 5 animals (L-arginine - prefrontal cortex), 4 animals (L-arginine - nucleus accumbens), 5 animals (L-NAME - prefrontal cortex), 4 animals (L-NAME - nucleus accumbens) 6 animals (ascorbate - prefrontal cortex) and 5 animals (ascorbate - nucleus accumbens). The sample data presented in Figs. 1-4 has been normalised and transformed to the average response obtained for the respective treatments. This removes both inter electrode and inter animal variability by ensuring that the 

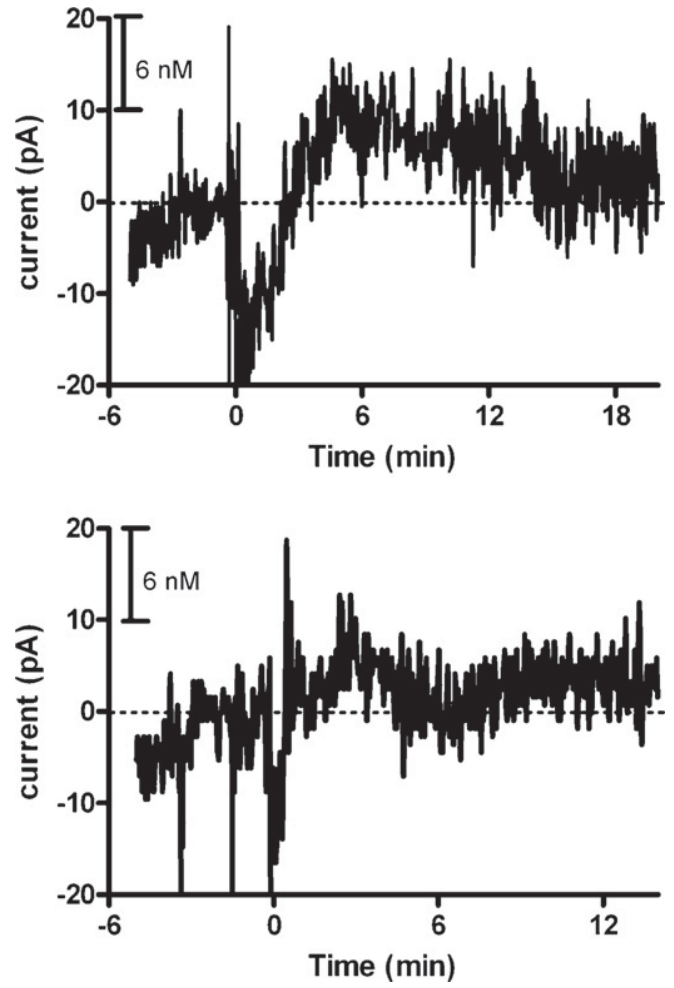

Fig. 1. Typical examples of the effect of saline administration ( $1 \mathrm{~mL}$ i.p. injection) monitored in rat prefrontal cortex (top, average pre-injection baseline $=317 \pm 14 \mathrm{pA}, n=17$ ) and rat nucleus accumbens (bottom, average pre-injection baseline $=324 \pm 37 \mathrm{pA}, n=8$ ) with a $\mathrm{Nafion}^{\circledR}(5 / 2)$-modified Pt sensor. Time zero indicates point of injection.

presented current and concentration changes are representative of the data from all the animals used in each study.

\subsection{Experimental conditions}

All experiments were carried out with the animal in its home bowl. Implanted electrodes were connected to the potentiostat through a six-pin Teflon ${ }^{\circledR}$ socket and a flexible screened six core cable which was mounted through a swivel above the rats head (Semat Technical) at least 7-8 h prior to the start of the first experiment each day. This arrangement allowed free movement of the animal.

\subsection{Voltammetry techniques in vivo}

All in vivo experiments utilised constant potential amperometry which involves the application of a constant voltage. The resulting current is directly proportional to the concentration of the analyte at any given time. NO was detected by holding the implanted sensor at the oxidation potential of $+900 \mathrm{mV}$ (vs. Ag wire) which has been previously characterised as the optimum potential for NO detection (Brown, 2003; Brown et al., 2009).

\section{Results and discussion}

\subsection{Systemic administrations}

Since all administrations were by i.p. injection it was important to examine the effect of normal saline administrations $(0.9 \%)$ on the oxidation current. We have previously reported a significant but short lived change ( $22 \pm 3 \mathrm{pA}, p<0.001, n=9)$ from baseline levels in NO sensor's implanted in the striatum of Wistar rats following
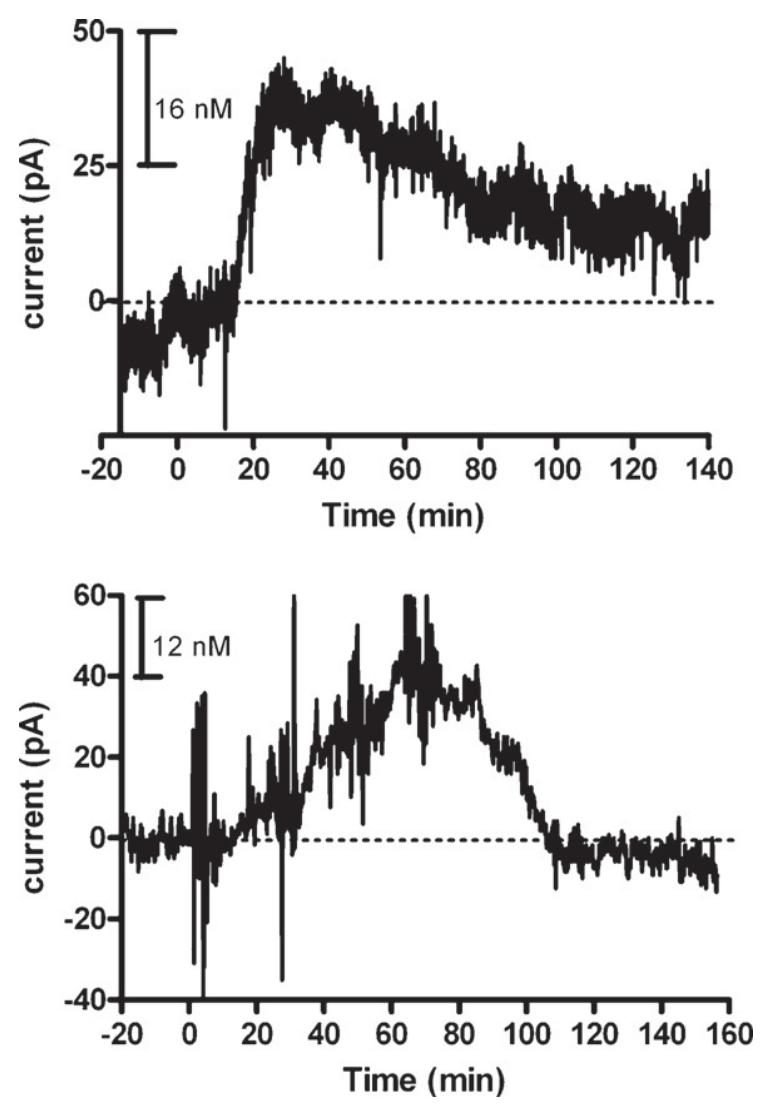

Fig. 2. Typical examples of the effect of L-arginine administration $\left(300 \mathrm{mg} \mathrm{kg}^{-1}\right.$, $1 \mathrm{~mL}$ i.p. injection) monitored in rat prefrontal cortex (top, average pre-injection baseline $=394 \pm 94 \mathrm{pA}, n=9$ ) and rat nucleus accumbens (bottom, average preinjection baseline $=245 \pm 25 \mathrm{pA}, n=8$ ) with a $\mathrm{Nafion}^{\circledR}(5 / 2)$-modified Pt sensor. Time zero indicates point of injection.

saline injection (Finnerty et al., 2012). Similar initial and brief injection effects have also been observed for tissue $\mathrm{O}_{2}$ (Bolger et al., 2011) and regional cerebral blood flow (rCBF) (Lowry and Fillenz, 2001) during the injection of saline, with a comparable return to baseline levels. A significant increase in the recorded current $(13 \pm 3 \mathrm{pA}, p<0.001, n=17)$ was observed in the prefrontal cortex, reaching a maximum level after $5 \pm 1 \mathrm{~min}(n=17)$ and returning to a baseline level after $12 \pm 2 \mathrm{~min}$. This short lived increase in oxidation current corresponded to a concentration change of ca. $8 \pm 2 \mathrm{nM}$. A similar affect was observed in the nucleus accumbens following saline administrations. A transient increase in oxidation current ( $12 \pm 3 \mathrm{pA}, n=8)$ occurred after $4 \pm 2 \mathrm{~min}$. This resulted in a significant increase from baseline $(p<0.05)$ that represented a concentration change of $7 \pm 4 \mathrm{nM}(n=8)$. The current returned to a baseline level after $8 \pm 3 \mathrm{~min}$. Typical examples of the effect of saline administration in both regions are shown in Fig. 1. The stress of the i.p. injection stimulates neuronal activation (Vahabzadeh and Fillenz, 1994), increasing rCBF and thus $\mathrm{O}_{2}$, with the supply of the latter exceeding utilisation. The observed increase in blood flow can be attributed to vasodilation brought about by NO through its physiological function as the EDRF (Ignarro et al., 1987; Palmer et al., 1987). The different roles that NO has to play in the body are dependent on which type of NOS enzyme is used in its synthesis. The constitutive forms (endothelial (eNOS) and neuronal (nNOS)) which are activated by $\mathrm{Ca}^{2+}$, followed by binding to the protein calmodulin, exert their effects through blood flow and neurotransmission respectively (Marletta, 1993). These findings corroborate previous reports that were carried out in the striatum of freely moving rats utilising the amperometric NO sensor (Finnerty et al., 2012). 

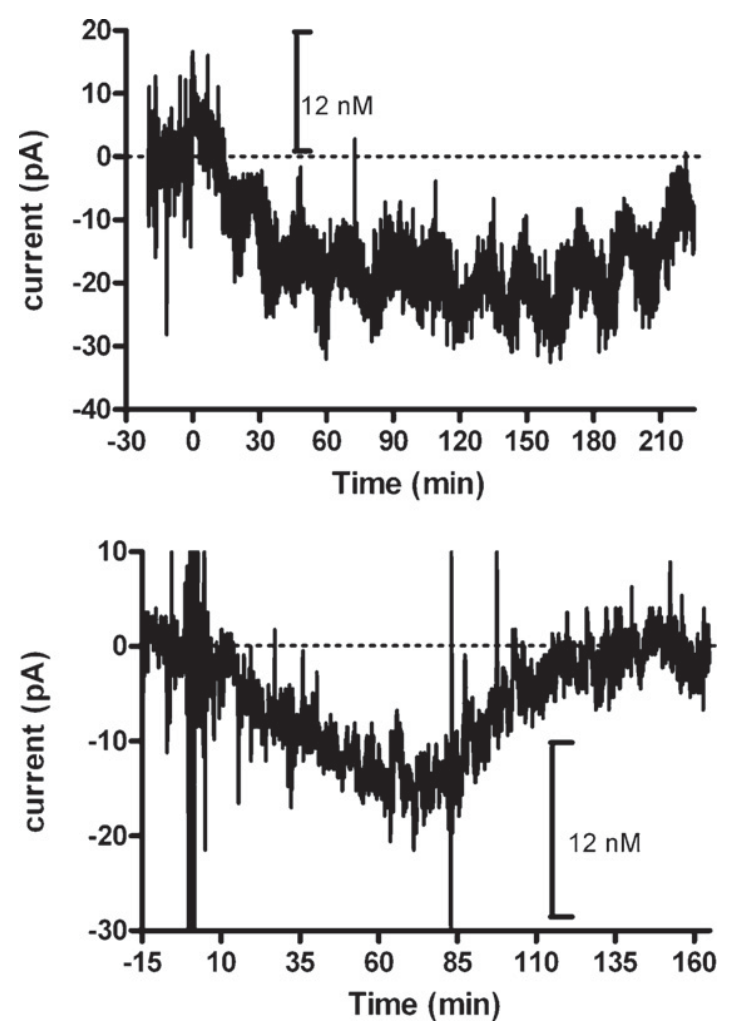

Fig. 3. Typical examples of the effect of L-NAME administration $\left(30 \mathrm{mg} \mathrm{kg}^{-1}, 1 \mathrm{~mL}\right.$ i.p. injection) monitored in rat prefrontal cortex (top, average pre-injection baseline $=311 \pm 38 \mathrm{pA}, n=5$ ) and rat nucleus accumbens (bottom, average pre-injection baseline $=407 \pm 107 \mathrm{pA}, n=6$ ) with a Nafion ${ }^{\circledR}(5 / 2)$-modified Pt sensor. Time zero indicates point of injection.

The reaction of L-arginine with molecular $\mathrm{O}_{2}$ in the presence of NO synthase results in the formation of NO and L-citrulline in equimolar quantities. Recent studies have demonstrated that arginine availability is an important condition for the physiological functioning of the nitroergic system (Do et al., 2002; Savel'ev

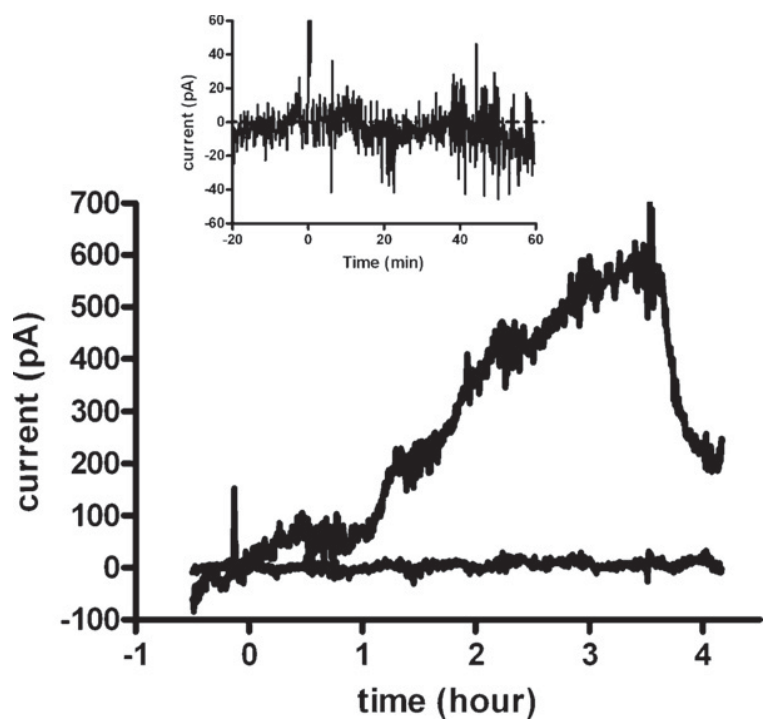

Fig. 4. Typical example of the effect of an i.p injection of sodium ascorbate $\left(2 \mathrm{~g} \mathrm{~kg}^{-1}\right.$ average pre-injection baseline $=359 \pm 56 \mathrm{pA}, n=13$ ) on currents monitored in prefrontal cortex with a Nafion ${ }^{\circledR}(5 / 2)$-modified Pt sensor and carbon paste electrode (CPE). Time zero indicates point of injection. Inset: Typical example of the effect of an i.p. injection of sodium ascorbate on a 60 min response of a Nafion ${ }^{\circledR}(5 / 2)$-modified Pt sensor implanted in the prefrontal cortex. and Saul'skaya, 2007). Indirect reports confirm the antioxidant effects of L-arginine in the early and late stages of ischaemia (Maksimovich et al., 2006) and its reduction in brain edema formation and improvement of cortical blood flow in the early phase after a brain trauma (Lundblad and Bentzer, 2007). Previously our group has confirmed in real-time that both systemic and local L-arginine administration significantly increased the NO sensor's signal in the striatum of Wistar rats compared to pre-administration baseline levels (Brown et al., 2009; Finnerty et al., 2012). Typical examples of the effect of L-arginine injections in the prefrontal cortex (top) and nucleus accumbens (bottom) are detailed in Fig. 2. A significant increase was observed in both the prefrontal cortex $(43 \pm 9 \mathrm{pA}, p<0.01, n=9)$ and nucleus accumbens $(44 \pm 9, p<0.01$, $n=8)$ in comparison to pre-injection baselines. These corresponded to concentration changes of $27 \pm 6 \mathrm{nM}(n=9)$ and $28 \pm 5 \mathrm{nM}(n=8)$ respectively. The maximum increase was recorded at $42 \pm 9 \mathrm{~min}$ $(n=9)$ in the prefrontal cortex before returning to baseline levels after $136 \pm 15 \min (n=9)$. In the nucleus accumbens the maximum response was achieved after $65 \pm 10 \mathrm{~min}(n=8)$ and returned to pre-injection levels after $153 \pm 12 \mathrm{~min}(n=8)$. These observations confirm that the NO sensor is responding to increased production of endogenous NO in both regions validating previous findings from other groups who reported an increase in NO current accompanying L-arginine perfusion, using an amperometric NO sensor implanted in the hippocampus of rats (Heinzen and Pollack, 2003, 2002). Previously, similar reports have detailed carbon fibre microelectrodes utilised for NO measurements in the corpus cavernosum of urethane-anaesthetised rats recorded enhancements in the NO signal following arginine administration (Escrig et al., 1999; Mas et al., 2002). Also, Carvalho et al. (2004) reported real-time in vitro measurements of $\mathrm{NO}$ production in erythrocytes using a commercial NO sensor during stimulation by L-arginine.

L-NAME is a non-selective nitric oxide synthase (NOS) inhibitor which acts by competing with L-arginine for its binding site on the NOS enzyme (Alderton et al., 2001). Microdialysis investigations have provided indirect evidence relating to decreases in co-product L-citrulline levels in the dorsal striatum following local infusion of various NOS inhibitors, L-NAME (Ohta et al., 1994) and in the nucleus accumbens following $N$-nitro-L-arginine (Saulskaya and Fofonova, 2006). L-Citrulline displays much greater chemical stability than NO which has resulted in the development of a series of indirect methods based on studies of citrulline synthesis in the nucleus accumbens for assessing NO production (Saul'skaya and Fofonova, 2009; Saul'skaya et al., 2008; Savel'ev and Saul'skaya, 2007). Recently we reported a significant decrease in NO $(91 \pm 19 \mathrm{pA}, p<0.05, n=4)$ compared to baseline levels following L-NAME administration in the striatum of Wistar rats (Finnerty et al., 2012). A typical example of the effects of a $30 \mathrm{mg} \mathrm{kg}^{-1}$ i.p. injection in both the prefrontal cortex and nucleus accumbens are illustrated in Fig. 3. The signal $(\Delta I)$ decreased significantly by $24 \pm 6 \mathrm{pA}(n=5, p<0.05)$ and $17 \pm 3 \mathrm{pA}(n=6, p<0.01)$ respectively compared to baseline levels. A maximum response was observed at $51 \pm 12 \min (n=5)$ in the prefrontal cortex that returned to baseline levels after $184 \pm 72 \mathrm{pA}(n=5)$. A similar observation was reported in the nucleus accumbens with a maximum decrease occurring at $60 \pm 6 \mathrm{~min}(n=6)$ and returning to pre-injection levels after $171 \pm 27 \mathrm{~min}(n=6)$. The current changes corresponded to concentration changes of $15 \pm 4 \mathrm{nM}(n=5)$ and $11 \pm 2 \mathrm{nM}(n=6)$ in the prefrontal cortex and nucleus accumbens respectively. These findings corroborate investigations undertaken by Escrig et al. (1999) in the corpus cavernosum whereby local and systemic administrations of L-NAME caused a decrease in NO levels. Indirect reports detailing L-NAME have shown that the NOS inhibitor attenuates or completely blocks the effects of phencyclidine hydrochloride (PCP), an NMDA receptor antagonist that is assumed to carry out its actions through an NO-mediated mechanism (Wass et al., 2006a,b; 
Wiley, 1998). A number of behavioural studies incorporating a series of different paradigms have confirmed this, for example, prepulse inhibition, which is the reduction in startle amplitude to a startling stimulus when this stimulus is immediately preceded by a weaker pre-stimulus (Klamer et al., 2001, 2004b). Another is latent inhibition, which is a referral to a phenomenon whereby preexposure to a stimulus weakens the subsequent association of that stimulus with a reinforcer in classical conditioning (Klamer et al., 2005; Palsson et al., 2005). We have recently reported direct evidence that $10 \mathrm{mg} \mathrm{kg}^{-1}$ L-NAME injections inhibit NO production following systemic administration of PCP (Palsson et al., 2009) confirming the postulations of the previous behavioural investigations. Other paradigms reported include the elevated plus-maze which is based on exploratory behaviour of rats. NO is believed to play a role in learning and memory and L-NAME is shown to induce a learning deficit in this avoidance learning test (Da Cunha et al., 2005). Since nitric oxide has been characterised as the EDRF, it is very closely associated with CBF and cerebrovasodilation. A number of existing reports have reported that L-NAME induced a reduction in levels of $\mathrm{CBF}$ that were increased following a period of hyperbaric oxygen exposure by a nitric oxide mediated mechanism (Demchenko et al., 2000, 2001; Hagioka et al., 2005). Yan et al. (2003) also reported a decrease in $\mathrm{CBF}$ in response to intravenous infusion of the NO synthase inhibitor at doses of $1,3,10$ and $30 \mathrm{mg} \mathrm{kg}^{-1}$.

\subsection{Interference studies}

Previously the Nafion ${ }^{\circledR}(5 / 2)$-modified Pt NO sensor demonstrated excellent selectivity towards NO in vitro against a wide range of electroactive interferents (e.g. ascorbic acid, dopamine, DOPAC, $\mathrm{NO}_{2}{ }^{-}$, serotonin) found endogenously in brain extracellular fluid (Brown et al., 2009). In vivo investigations in the striatum of freely moving rats displayed excellent rejection characteristics against ascorbate (Finnerty et al., 2012), the most abundantly present interferent reported in the ECF with a hypothesised concentration of ca. $500 \mu \mathrm{M}$ (Miele and Fillenz, 1996). It is imperative to confirm that the Nafion ${ }^{\circledR}$ membrane has not degraded when placed in the in vivo environment and that the sensor exhibits similar selectivity characteristics to those recorded in vitro (Brown et al., 2009; Brown and Lowry, 2003). With its high concentration and ease of oxidation, ascorbate is probably the simplest molecule to detect and monitor in brain ECF using in vivo voltammetry techniques (Lowry and O'Neill, 2006; O'Neill et al., 1998). For these reasons it was important to investigate the effect of systemic administrations of ascorbate on the Nafion ${ }^{\circledR}$-modified Pt sensor current in both the prefrontal cortex and nucleus accumbens. The current was monitored over a $60 \mathrm{~min}$ period as previous investigations have reported this time frame allows for a maximum response to occur (Finnerty et al., 2012; Lowry et al., 1996). It is hypothesised that any effect following ascorbate injection will have occurred within this period. Fig. 4 (inset) illustrates this effect from a Nafion ${ }^{\circledR}(5 / 2)$-modified Pt NO sensor implanted in the nucleus accumbens. There was a slight decrease in the oxidation current over the course of ascorbate injections in both brain regions that can be attributed to baseline drift recorded over the 60 mins. There was no significant difference in signal against baseline levels in the prefrontal cortex $(-8 \pm 16 \mathrm{pA}, p>0.05, n=13)$ and the nucleus accumbens $(-16 \pm 17 \mathrm{pA}, p>0.05, n=10)$ recorded over the $60 \mathrm{~min}$ period. Fig. 4 displays a comparison between a typical example of the effect of ascorbate injection $\left(2 \mathrm{~g} \mathrm{~kg}^{-1}\right)$ on a carbon paste electrode and the Nafion ${ }^{\circledR}(5 / 2)$-modified Pt NO sensor implanted in the prefrontal cortex. It is clearly evident that there is a difference in the signal elicited from both sensors following administration of the interferent. This comparison provides validation that ascorbate has reached both sensors and no increase at the Nafion ${ }^{\circledR}(5 / 2)$-modified Pt NO sensor was observed, confirming that the NO sensor's surface has remained intact. A similar observation was noted in the nucleus accumbens. Collectively these results corroborate previous investigations undertaken in the striatum of freely moving rats (Finnerty et al., 2012).

\subsection{Regional comparisons}

Table 1 summarises the in vivo characterisation data for Nafion ${ }^{\circledR}(5 / 2)$-modified sensors implanted in the striatum, prefrontal cortex and nucleus accumbens of freely moving rats. It is apparent from these investigations that alternative sources of NO production may be responsible for differences observed between brain regions. The constitutive isoforms of NOS (eNOS and nNOS) are the primary source of $\mathrm{NO}$ production in the brain lending support to its hypothesised function as a signalling molecule in the central nervous system. iNOS is primarily linked with pathological situations and is rarely present at tonic levels but is expressed in various cell types such as macrophages and microglia (Garthwaite, 2008). It is imperative that we consider regional variations in determining parameters such as NOS activity and NOS expression, highlighting the fact that there may be multiple sources of NO production and inhibition within a tissue matrix. In the dorsal striatum, projection neurons comprise $90 \%$ of all the cells; however, interneurons comprise only $10 \%$ of striatal cells and are implicated in regulating striatal projection function. It is the interneurons that are the primary source of nNOS in this brain region (Kawaguchi and Emson, 1996; Marin et al., 2000).

The ventral striatum (nucleus accumbens) contains NO generating interneurons that receive excitatory glutamatergic and dopaminergic inputs from the hippocampus and ventral tegmental area respectively (Saulskaya and Fofonova, 2006). A high density of NMDA receptors has been confirmed in the prefrontal cortex (Monaghan and Cotman, 1985) and it is postulated that NO exerts strong influence on glutamatergic neurotransmission by directly interacting with the receptor (Bernstein et al., 2005). Various other reports have indicated that NOS activity was decreased in the hippocampus of aged rats but not in the cortex or cerebellum (Mollace et al., 1995; Vallebuona and Raiteri, 1995), however, alternative investigators reported increased activity in both the hippocampus and cerebellum of aged rats (Chalimoniuk and Strosznajder, 1998). These findings have all been quantified by indirect methods which is a major disadvantage of the vast majority of existing analytical techniques. The Nafion ${ }^{\circledR}(5 / 2)$-modified Pt NO sensor described here represents a major advancement in measuring physiologically meaningful NO levels in real-time and over extended periods.

Saline administrations resulted in transient increases from baseline that had returned to pre-injection baselines within a $15 \mathrm{~min}$ time frame across all brain regions. It is a well accepted phenomenon that injection stress causes an increase in neuronal activation which is closely linked to CBF (Vahabzadeh and Fillenz, 1994). The larger blood vessels are supplied with nitrergic nerves that once activated, result in NO release, vasodilation and increased blood flow (Garthwaite, 2008; Toda and Okamura, 2003). Fig. 5 (top) compares the effect of saline injections on the oxidation current recorded in the three regions with an elevated response observed in the striatum. A significant difference $(p<0.05)$ was observed when comparing the current changes in the striatum $(22 \pm 3, n=9)$ and nucleus accumbens $(12 \pm 3 \mathrm{pA}, n=8)$ following injections. No significant difference $(p>0.05)$ was observed between the striatum and prefrontal cortex $(13 \pm 3 \mathrm{pA}, n=17)$ or between the prefrontal cortex and nucleus accumbens in terms of $\Delta I$ changes from baseline levels. A number of factors must be taken into account when interpreting these findings. The NO may be generated from eNOS located in the microvascular network and capillary circulation that can be attributed to a rise in CBF following stress brought about by systemic administration. The implantation site of the 


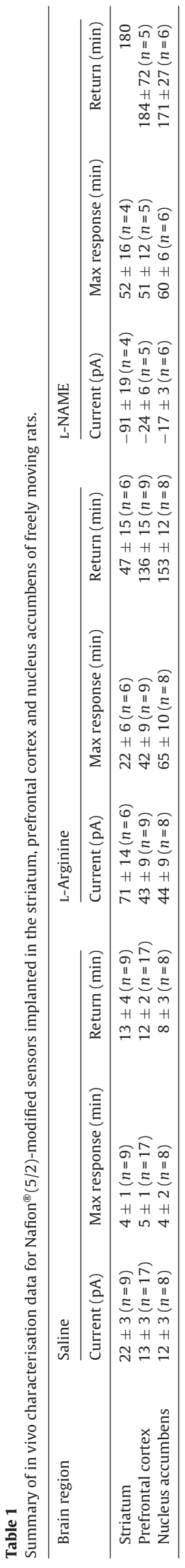

Nafion ${ }^{\circledR}(5 / 2)$-modified Pt NO sensor's may be situated in closer proximity to vasculature circuitry when inserted into the striatum giving rise to the larger NO signals recorded in this region. This may not be the case for the sensors implanted in the nucleus accumbens and prefrontal cortex, providing a possible explanation for the different responses following saline administrations. A similar effect has been observed using carbon paste electrodes for real-time measurements of oxygen whereby, the concentration of oxygen observed can vary depending on the orientation of the electrode relative to the blood vessels and metabolically active sites, and on the depth of penetration into the tissue (Baumgärtl et al., 1989). Since the dimension (typically $100-200 \mu \mathrm{m}$ ) of carbon paste electrodes are greater than the scale of a capillary zone (ca. $70 \mu \mathrm{m}$ ) (Silver, 1965), an average tissue $\mathrm{O}_{2}$ level is detected (Bolger et al., 2011). This may translate across to observations reported here with the NO sensor since the three-dimensional geometry of the capillary circulation would be just as well suited for delivering NO globally to the electrode as it is for delivering $\mathrm{O}_{2}$ (Garthwaite, 2008). Other possible sources could be from postsynaptic NO production derived from nNOS, followed by diffusion into the extracellular space. This is a unique property that NO possesses over conventional neurotransmitters in that being a gaseous molecule it can diffuse freely between membranes and has functions both intracellularly and extracellularly. Kennedy (2000) reported that typical excitatory synapses in the brain could have ca. 50 NMDA receptors dispersed over a 400-nm-diameter postsynaptic density. Since NMDA receptors display a high association with nNOS, there is a strong possibility that they are a contributing factor to our observations. Further evidence provided by Monaghan and Cotman confirm high NMDA densities in the striatum, prefrontal cortex and nucleus accumbens of rats (Monaghan and Cotman, 1985).

Systemic administrations of the precursor L-arginine and the NOS inhibitor L-NAME displayed contrasting affects in the different brain regions investigated. Studies in recent years have demonstrated that arginine availability is an important condition for the functioning of the nitrergic system (Savel'ev and Saul'skaya, 2007). Tsikas et al. (2000) reported arginine saturation in cells causes the precursor to be present at concentrations far exceeding the $\mathrm{Km}$ value. A topic that instigates much discussion is why supplementation of the substrate enhances NO production in vivo. It is a well documented phenomenon referred to as the "arginine paradox". In the present study L-arginine produced long lasting effects in both the prefrontal cortex and nucleus accumbens that returned to pre-injection levels within a $180 \mathrm{~min}$ period. There was no significant difference $(p>0.05)$ between the three brain regions following systemic administrations as illustrated in Fig. 5 (middle), however, the striatal current returned to pre-injection levels much faster than the prefrontal cortex and nucleus accumbens. This is clearly evident from Table 1 and may be attributed to differences between brain regions. Indirect measurements of NO (nitrite and nitrate detection) following L-arginine administration have been well documented using the microdialysis technique. Local $(1 \mathrm{mM})$ and systemic ( $500 \mathrm{mg} \mathrm{kg}^{-1}$ ) administrations sufficiently induced an enhancement of NO production in the rat cerebellum (Yamada and Nabeshima, 1997). However, Hara et al. reported contradictory findings from the hippocampus and striatum using a similar indirect measurement. $500 \mathrm{mg} \mathrm{kg}^{-1}$ injections of L-arginine significantly increased extracellular hippocampal nitrite and nitrate levels in comparison to saline administrations. In complete contrast to our findings, they found that $500 \mathrm{mg} \mathrm{kg}^{-1}$ had no effect on the extracellular levels of the NO metabolites in the striatum (Hara et al., 2004). Their investigations postulate that the striatum might be less responsive to exogenous L-arginine in enhancing NO production via NOS than the hippocampus. The direct measurements using our Nafion ${ }^{\circledR}(5 / 2)$-modified Pt NO sensor suggest a very contradictory function in the striatum with sufficient detection 
of increases in NO levels ( $71 \pm 14 \mathrm{pA}, n=6)$. Although there were reduced responses observed in the prefrontal cortex $(43 \pm 9 \mathrm{pA}$, $n=9$ ) and nucleus accumbens ( $44 \pm 9 \mathrm{pA}, n=8$ ), they did not differ significantly from the striatum suggesting that the arginine paradox might not be equally applicable in all regions of the brain.

Fig. 5 (bottom) and Table 1 detail the varying effect of L-NAME administration on the Nafion ${ }^{\circledR}(5 / 2)$-modified Pt NO sensor in all three brain regions. There are significant differences $(p<0.01)$ reported between the striatum $(-91 \pm 19 \mathrm{pA}, n=4)$ and the prefrontal cortex $(-24 \pm 6 \mathrm{pA}, n=5)$ and nucleus accumbens $(-17 \pm 3 \mathrm{pA}, n=6)$ respectively. No significant difference $(p>0.05)$ was observed between the prefrontal cortex and nucleus accumbens. One possible explanation for the regional variations may be due to the heterogenous distribution of NOS in the rat brain that affects determining parameters such as NOS expression and NOS inhibition within the tissue matrix. Various groups have provided indirect evidence of the effect of the NOS inhibitor on NO levels in the prefrontal cortex using microdialysis investigations (Laitinen et al., 1994, 1997; Pepicelli et al., 2004). L-NAME and another NOS inhibitor L-NARG failed to diminish cGMP levels in the frontal cortex of rats, however, these findings are difficult to interpret as they provide indirect evidence of NO activity in the region. They may provide some corroboration with our investigations since significantly reduced NO inhibition was observed in the prefrontal cortex in contrast to the striatum. Contrasting evidence provided by Fedele and Raiteri (1999) in the rat cerebellum and hippocampus reported that reterodialysis administration of NOS inhibitors markedly decreased extracellular cGMP in both regions. Collectively this evidence postulates that NOS inhibition in the rat prefrontal cortex is controlled in a different way from what occurs in other brain regions, such as the cerebellum and hippocampus. Citrulline monitoring is extensively utilised as an alternative method of determining NO fluctuations indirectly in various brain regions. Ohta et al. (1994) have reported decreases in citrulline in the striatum following local infusion of L-NAME, a finding which lends further support to our observations. Saulskaya and Fofonova (2006) extend these observations by demonstrating that local administrations of a NOS inhibitor (L-NA) in the nucleus accumbens reduces citrulline levels suggesting that there may be tonic levels of NOS present in the nucleus accumbens, that initiate the formation of the co-product of NO production during homeostasis.

Considering that the NO sensors were implanted bilaterally in left and right hemispheres of the nucleus accumbens, it was of interest to compare the effect of injections on contralateral placement in this brain region. Saline injections resulted in transient increases in NO signal in both the left $(19 \pm 1 \mathrm{pA}, n=2)$ and right $(10 \pm 4 \mathrm{pA}, n=6)$ hemispheres. There was no significant difference $(p>0.05)$ recorded between the two. A similar observation was reported for L-arginine injections. There was no significant difference $(p>0.05)$ between responses from the Nafion ${ }^{\circledR}(5 / 2)$ modified Pt sensors implanted in the left $(53 \pm 9 \mathrm{pA}, n=2)$ and right $(44 \pm 11 \mathrm{pA}, n=6)$ sides of the nucleus accumbens. L-NAME administrations produced similar findings from sensors situated contralateral to each other in this region. NO signals in the left hemispheres $(-16 \pm 3 \mathrm{pA}, n=2)$ displayed no significant difference $(p>0.05)$ from those situated in the right hemisphere $(-18 \pm 4 \mathrm{pA}$, $n=4)$ of the accumbens. These findings confirm that there are no significant differences observed between NO signals recorded in opposite hemispheres confirming the viability of the $\mathrm{Nafion}^{\circledR}(5 / 2)$ modified Pt sensors in contralateral investigations in the rat brain.

All of the aforementioned illustrate the complexity of NO determinations utilising both direct and indirect analytical methods. However, it is our understanding that this report provides the first extensive and in depth comparison of real-time investigations detailing the variations in endogenous NO determined in a variety
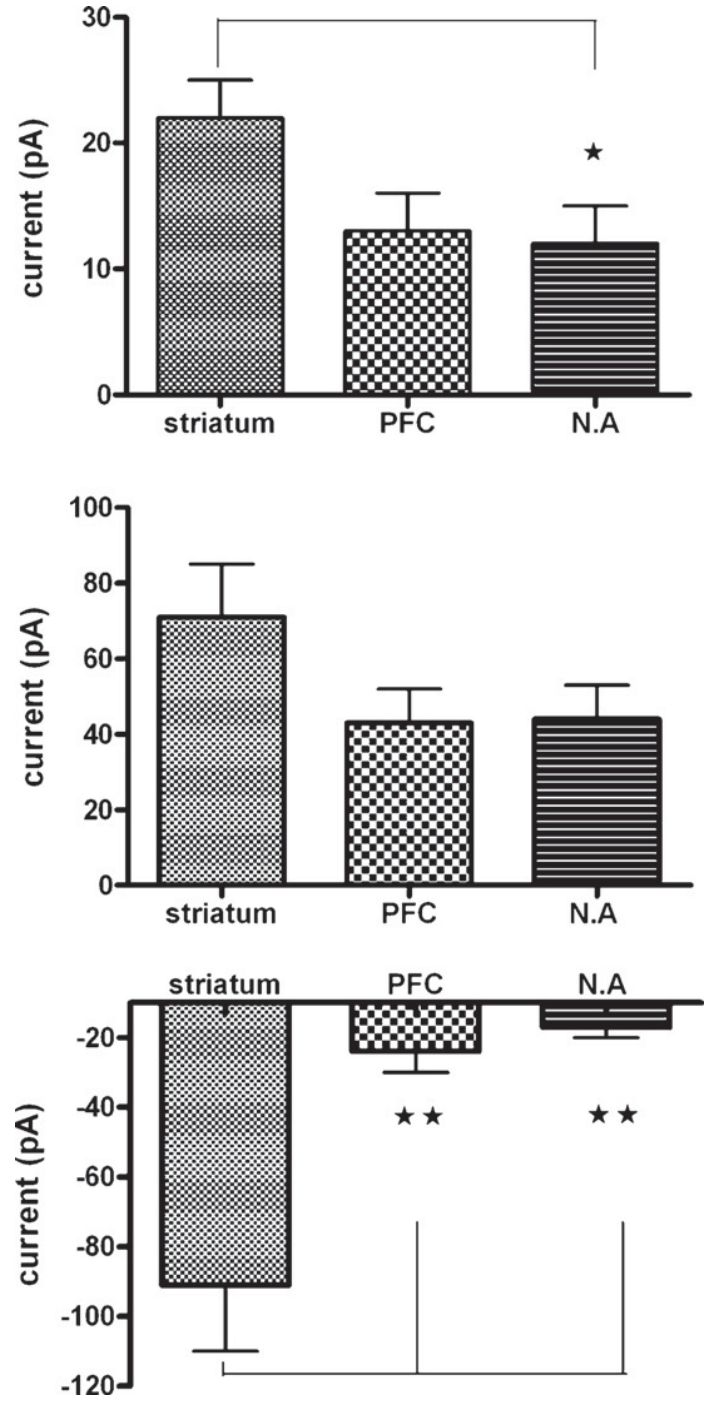

Fig. 5. Comparison of the effect of saline (top), L-arginine (middle) and L-NAME (bottom) on Nafion ${ }^{\circledR}(5 / 2)$-modified Pt sensor signal recorded in striatum, prefrontal cortex (PFC) and nucleus accumbens (NA). Data is expressed as mean $\Delta I \pm$ SEM as compared to baseline. (top) $\star$ denotes a significant difference between striatum and nucleus accumbens $(p<0.05)$ and (bottom) $\star \star$ denotes a significant difference between striatum and prefrontal cortex $(p<0.01)$ and between striatum and nucleus accumbens $(p<0.01)$

of brain regions. The Nafion ${ }^{\circledR}(5 / 2)$-modified Pt NO sensor detailed within possesses the necessary sensitivity, spatial and temporal precision for specific applications in animal model studies.

\section{Conclusion}

We have reported the in vivo characterisation of a Nafion ${ }^{\circledR}(5 / 2)$ modified Pt NO sensor in the prefrontal cortex and nucleus accumbens of freely moving rats. Previously we have demonstrated the efficacy of the NO sensor in the striatum using local and systemic administrations. Saline injections caused transient increases in oxidation current in both the prefrontal cortex and nucleus accumbens against baseline levels which was attributed to the stress of the i.p. injection stimulating neuronal activation. L-Arginine injections produced significant increases in the NO signal in both regions. Systemic administrations of the non selective NOS inhibitor LNAME resulted in significant decreases in the recorded current measured using the Nafion ${ }^{\circledR}(5 / 2)$-modified Pt NO sensor. Ascorbate selectivity studies confirmed minimal deterioration of the Nafion ${ }^{\circledR}$ 
modified surface. A critical comparison of the in vivo characterisation undertaken in the striatum, prefrontal cortex and nucleus accumbens identified significantly greater affects of administrations on NO sensors implanted in the striatum than the other two regions. However, no definitive explanation can be provided for these interregional differences. In summary we have extensively characterised a highly selective and sensitive NO sensor in three different regions that is capable of measuring physiologically meaningful NO signals in real-time in the brain extracellular fluid.

\section{Acknowledgements}

We gratefully acknowledge financial support from the Analytical Chemistry Trust Fund, Royal Society of Chemistry (RSC) Analytical PhD Studentship 03/F/018, Enterprise Ireland (BR/1999/159), Science Foundation Ireland (03/IN3/B376) and the Centre of Applied Science for Health which is funded by the Higher Education Authority under the Programme for Research in Third Level Institutions (PRTLI) Cycle 4.

\section{References}

Alderton WK, Cooper CE, Knowles RG. Nitric oxide synthases: structure, function and inhibition. Biochem J 2001;357:593-615.

Barth A, Newell DW, Nguyen LB, Winn HR, Wender R, Meno JR, et al. Neurotoxicity in organotypic hippocampal slices mediated by adenosine analogues and nitric oxide. Brain Res 1997;762:79-88.

Baumgärtl H, Heinrich U, Lübbers D. Oxygen supply of the blood-free perfused guinea-pig brain in normo- and hypothermia measured by the local distribution of oxygen pressure. Pflügers Arch 1989;414:228-34.

Bernstein HG, Bogerts B, Keilhoff G. The many faces of nitric oxide in schizophrenia. A review. Schizophr Res 2005;78:69-86.

Bolger FB, McHugh SB, Bennett R, Li J, Ishiwari K, Francois J, et al. Characterisation of carbon paste electrodes for real-time amperometric monitoring of brain tissue oxygen. J Neurosci Methods 2011;195:135-42.

Brown FO. Development of a microelectrochemical sensor for monitoring brain extracellular nitric oxide. PhD thesis. NUI Maynooth; 2003, p. 55-8.

Brown FO, Finnerty NJ, Lowry JP. Nitric oxide monitoring in brain extracellular fluid: characterisation of Nafion ( $\mathrm{R}$ )-modified Pt electrodes in vitro and in vivo. Analyst 2009;134:2012-20.

Brown FO, Lowry JP. Microelectrochemical sensors for in vivo brain analysis: an investigation of procedures for modifying Pt electrodes using Nafion. Analyst 2003;128:700-5.

Bruckdorfer R. The basics about nitric oxide. Mol Aspects Med 2005;26:3-31.

Carvalho FA, Martins-Silva J, Saldanha C. Amperometric measurements of nitric oxide in erythrocytes. Biosens Bioelectron 2004;20:505-8.

Chalimoniuk M, Strosznajder JB. Aging modulates nitric oxide synthesis and cGMP levels in hippocampus and cerebellum - effects of amyloid beta peptide. Mol Chem Neuropathol 1998;35:77-95

Da Cunha IC, Jose RF, Orlandi Pereira L, Pimenta JA, Oliveira de Souza IA, Reiser R, et al. The role of nitric oxide in the emotional learning of rats in the plus-maze. Physiol Behav 2005;84:351-8.

Dawson VL, Kizushi VM, Huang PL, Snyder SH, Dawson TM. Resistance to neurotoxicity in cortical cultures from neuronal nitric oxide synthase-deficient mice. J Neurosci 1996;16:2479-87.

Demchenko IT, Boso AE, Bennett PB, Whorton AR, Piantadosi CA. Hyperbaric oxygen reduces cerebral blood flow by inactivating nitric oxide. Nitric Oxide 2000;4:597-608.

Demchenko IT, Boso AE, Whorton AR, Piantadosi CA. Nitric oxide production is enhanced in rat brain before oxygen-induced convulsions. Brain Res 2001:917:253-61.

Do KQ Grima G, Benz B, Salt TE. Glial-neuronal transfer of arginine and Snitrosothiols in nitric oxide transmission. Ann NY Acad Sci 2002;962:81-92.

Escrig A, Gonzalez-Mora JL, Mas M. Nitric oxide release in penile corpora cavernosa in a rat model of erection. J Physiol 1999:516:261-9.

Espey MG, Thomas DD, Miranda KM, Wink DA. Focusing of nitric oxide mediated nitrosation and oxidative nitrosylation as a consequence of reaction with superoxide. Proc Natl Acad Sci USA 2002;99:11127-32.

Fedele E, Raiteri M. In vivo studies of the cerebral glutamate receptor NO cGMP pathway. Prog Neurobiol 1999;58:89-120.

Fejgin K, Palsson E, Wass C, Svensson L, Klamer D. Nitric oxide signaling in the medial prefrontal cortex is involved in the biochemical and behavioral effects of phencyclidine. Neuropsychopharmacology 2008;26:26.

Finnerty NJ, O'Riordain SL, Brown FO, Serra PA, O'Neill RD, Lowry JP. In vivo characterisation of a Nafion-modified Pt electrode for real-time nitric oxide monitoring in brain extracellular fluid. Anal Methods 2012;4:550-7.

Garthwaite J. Concepts of neural nitric oxide-mediated transmission. Eur J Neurosci 2008;27:2783-802.
Hagioka S, Takeda Y, Zhang S, Sato T, Morita K. Effects of 7-nitroindazole and Nnitro-L-arginine methyl ester on changes in cerebral blood flow and nitric oxide production preceding development of hyperbaric oxygen-induced seizures in rats. Neurosci Lett 2005;382:206-10.

Hara S, Mukai T, Kurosaki K, Mizukami H, Kuriiwa F, Endo T. Different response to exogenous L-arginine in nitric oxide production between hippocampus and striatum of conscious rats: a microdialysis study. Neurosci Lett 2004;366:302-7.

Heinzen EL, Pollack GM. Pharmacokinetics and pharmacodynamics of L-arginine in rats: a model of stimulated neuronal nitric oxide synthesis. Brain Res 2003;989:67-75.

Heinzen EL, Pollack GM. Use of an electrochemical nitric oxide sensor to detect neuronal nitric oxide production in conscious, unrestrained rats. J Pharmacol Toxicol Methods 2002;48:139-46.

Ignarro LJ, Buga GM, Wood KS, Byrns RE, Chaudhuri G. Endothelium-derived relaxing factor produced and released from artery and vein is nitric oxide. Proc Natl Acad Sci USA 1987;84:9265-9.

Kawaguchi Y, Emson PC. Striatal interneurones: chemical, physiological and morphological characterization (vol. 18, p. 527, 1995). Trends Neurosci 1996;19:143.

Kelm M. Nitric oxide metabolism and breakdown. Biochim Biophys Acta 1999;1411:273-89.

Kennedy MB. Signal-processing machines at the postsynaptic density. Science 2000;290:750-4.

Kiechle FL, Malinski T. Nitric oxide. Biochemistry, pathophysiology, and detection. Am J Clin Pathol 1993;100:567-75.

Klamer D, Engel JA, Svensson L. The neuronal selective nitric oxide synthase inhibitor, N-omega-propyl-L-arginine, blocks the effects of phencyclidine on prepulse inhibition and locomotor activity in mice. Eur J Pharmacol 2004a;503:103-7.

Klamer D, Engel JA, Svensson L. The nitric oxide synthase inhibitor, L-NAME, block phencyclidine-induced disruption of prepulse inhibition in mice. Psychopharmacology (Berl) 2001;156:182-6

Klamer D, Palsson E, Revesz A, Engel JA, Svensson L. Habituation of acoustic startle is disrupted by psychotomimetic drugs: differential dependence on dopaminergic and nitric oxide modulatory mechanisms. Psychopharmacology (Berl) 2004b;176:440-50.

Klamer D, Palsson E, Wass C, Archer T, Engel JA, Svensson L. Antagonism of the nitric oxide synthase inhibitor, L-NAME, of the effects of phencyclidine on latent inhibition in taste aversion conditioning. Behav Brain Res 2005;161:60-8.

Laitinen JT, Laitinen KSM, Tuomisto L, Airaksinen MM. Differential regulation of cyclic-GMP levels in the frontal-cortex and the cerebellum of anesthetized rats by nitric-oxide - an in vivo microdialysis study. Brain Res 1994;668:117-21.

Laitinen KSM, Salovaara K, Severgnini S, Laitinen JT. Regulation of cyclic GMP levels in the rat frontal cortex in vivo: effects of exogenous carbon monoxide and phosphodiesterase inhibition. Brain Res 1997;755:272-8.

Lowry JP, Boutelle MG, Fillenz M. Measurement of brain tissue oxygen at a carbon past electrode can serve as an index of increases in regional cerebral blood flow. J Neurosci Methods 1997:71:177-82.

Lowry JP, Boutelle MG, O’Neill RD, Fillenz M. Characterization of carbon paste electrodes in vitro for simultaneous amperometric measurement of changes in oxygen and ascorbic acid concentrations in vivo. Analyst 1996;121: 761-6.

Lowry JP, Fillenz M. Real-time monitoring of brain energy metabolism in vivo using microelectrochemical sensors: the effects of anesthesia. Bioelectrochemistry 2001;54:39-47

Lowry JP, O'Neill RD. Neuroanalytical chemistry in vivo using electrochemical sensors. ENC Sensors 2006;10:1-23.

Lundblad C, Bentzer P. Effects of L-arginine on cerebral blood flow, microvascular permeability, number of perfused capillaries, and brain water content in the traumatized mouse brain. Microvasc Res 2007;74:1-8.

Maksimovich NE, Zinchuk VV, Maslakov DA. The degree of oxidative stress in the rat brain during ischemia and reperfusion in conditions of correction of the Larginine-NO system. Neurosci Behav Physiol 2006;36:373-8.

Marin O, Anderson SA, Rubenstein JLR. Origin and molecular specification of striatal interneurons. J Neurosci 2000;20:6063-76.

Marletta MA. Nitric oxide synthase structure and mechanism. J Biol Chem 1993;268:12231-4.

Mas M, Escrig A, Gonzalez-Mora JL. In vivo electrochemical measurement of nitric oxide in corpus cavernosum penis. J Neurosci Methods 2002;119: 143-50.

Miele M, Fillenz M. In vivo determination of extracellular brain ascorbate. J Neurosci Methods 1996;70:15-9.

Miller EK, Cohen JD. An integrative theory of prefrontal cortex function. Annu Rev Neurosci 2001;24:167-202.

Mollace V, Rodino P, Massoud R, Rotiroti D, Nistico G. Age-dependent changes of no synthase activity in the rat-brain. Biochem Biophys Res Commun 1995:215:822-7.

Monaghan DT, Cotman CW. Distribution of N-methyl-D-aspartate-sensitive L-[H3]glutamate-binding sites in rat-brain. J Neurosci 1985;5:2909-19.

O'Neill RD, Lowry JP, Mas M. Monitoring brain chemistry in vivo: voltammetric techniques, sensors, and behavioral applications. Crit Rev Neurobiol 1998;12:69-127.

Ohta K, Shimazu K, Komatsumoto S, Araki N, Shibata M, Fukuuchi Y. Modification of striatal arginine and citrulline metabolism by nitric-oxide synthase inhibitors. Neuroreport 1994;5:766-8.

Palmer RM, Ferrige AG, Moncada S. Nitric oxide release accounts for the biological activity of endothelium-derived relaxing factor. Nature 1987;327:524-6. 
Palsson E, Finnerty N, Fejgin K, Klamer D, Wass C, Svensson L, et al. Increased cortical nitric oxide release after phencyclidine administration. Synapse 2009;63:1083-8.

Palsson E, Klamer D, Wass C, Archer T, Engel JA, Svensson L. The effects of phencyclidine on latent inhibition in taste aversion conditioning: differential effects of preexposure and conditioning. Behav Brain Res 2005;157:139-46.

Paxinos G, Watson C. The rat brain in stereotaxic coordinates. Academic Press; 1998.

Pepicelli O, Brescia A, Gherzi E, Raiteri M, Fedele E. GABA(A), but not NMDA, receptors modulate in vivo NO-mediated cGMP synthesis in the rat cerebral cortex. Neuropharmacology 2004;46:480-9.

Radomski MW, Palmer RM, Moncada S. An L-arginine/nitric oxide pathway present in human platelets regulates aggregation. Proc Natl Acad Sci USA 1990;87:5193-7.

Saul'skaya NB, Fofonova NV. Dopamine D1 receptors regulate the extracellular citrulline level in the nucleus accumbens during performance of a conditioned reflex fear reaction. Neurosci Behav Physiol 2009;39:335-40.

Saul'skaya NB, Fofonova NV, Savel'ev SA. Glutamatergic regulation of extracellular citrulline levels in the nucleus accumbens during an emotional conditioned reflex. Neurosci Behav Physiol 2008;38:487-92.

Saulskaya NB, Fofonova NV. Effects of N-methyl-D-aspartate on extracellular citrulline level in the rat nucleus accumbens. Neurosci Lett 2006;407:91-5.

Savel'ev SA, Saul'skaya NB. Extracellular citrulline levels in the nucleus accumbens during the acquisition and extinction of a classical conditioned reflex with pain reinforcement. Neurosci Behav Physiol 2007;37:249-56.

Silver I. Some observations on the cerebral cortex with an ultra-micro, membrane covered, oxygen electrode. Med Electron Biol Eng 1965;3:377-87.

Toda N, Okamura T. The pharmacology of nitric oxide in the peripheral nervous system of blood vessels. Pharmacol Rev 2003;55:271-324.
Tsikas D, Boger RH, Sandmann J, Bode-Boger SM, Frolich JC. Endogenous nitric oxide synthase inhibitors are responsible for the L-arginine paradox. FEBS Lett 2000;478:1-3.

Tzschentke TM. Pharmacology and behavioral pharmacology of the mesocortical dopamine system. Prog Neurobiol 2001;63:241-320.

Vahabzadeh A, Fillenz M. Comparison of stress-induced changes in noradrenergic and serotonergic neurons in the rat hippocampus using microdialysis. Eur J Neurosci 1994;6:1205-12.

Vallebuona F, Raiteri M. Age-related-changes in the NMDA receptor nitric oxide/cGMP pathway in the hippocampus and cerebellum of freely moving rats subjected to transcerebral microdialysis. Eur J Neurosci 1995;7:694-701.

Wass C, Archer T, Palsson E, Fejgin K, Alexandersson A, Klamer D, et al. Phencyclidine affects memory in a nitric oxide-dependent manner: working and reference memory. Behav Brain Res 2006a;174:49-55.

Wass C, Archer T, Palsson E, Fejgin K, Klamer D, Engel JA, et al. Effects of phencyclidine on spatial learning and memory: nitric oxide-dependent mechanisms. Behav Brain Res 2006b;171:147-53.

Wiley JL. Nitric oxide synthase inhibitors attenuate phencyclidine-induced disruption of prepulse inhibition. Neuropsychopharmacology 1998;19:86-94.

Yamada K, Nabeshima T. Simultaneous measurement of nitrite and nitrate levels as indices of nitric oxide release in the cerebellum of conscious rats. J Neurochem 1997;68:1234-43.

Yan PG, Wu CF, Huang M, Liu W, Yang JY. Ascorbic acid antagonizes the inhibitory effect of acute ethanol on nitrite levels in the striatum of freely moving mice. Neurosci Lett 2003;352:183-6.

Yananli H, Goren MZ, Berkman K, Aricioglu F. Effect of agmatine on brain Lcitrulline production during morphine withdrawal in rats: a microdialysis study in nucleus accumbens. Brain Res 2007;1132:51-8. 